\title{
Peritonitis due to Rhizobium radiobacter
}

\author{
Peritonite por Rhizobium radiobacter \\ Raquel Marta ${ }^{1}$, Catarina Dâmaso² ${ }^{2}$ José Esteves da Silva ${ }^{3}$, Margarida Almeida ${ }^{3}$
}

\begin{abstract}
Rhizobium radiobacter (Agrobacterium radiobacter) is an aerobic Gram-negative rod belonging to Agrobacterium genus, a group of phytopathogenic bacteria present in the soil that has been implicated in human opportunistic infections. We report a clinical case of bacterial peritonitis in a 5-year-old child with chronic renal disease in peritoneal dialysis, who had a history of direct soil contact identified. The infection was treated with ceftazidime and piperaciline+tazobactam without relapses or the need to remove the peritoneal dialysis catheter.
\end{abstract}

Keywords: Rhizobium radiobacter; Peritonitis; Peritoneal dialysis; Child; Case reports

\section{RESUMO}

0 Rhizobium radiobacter (Agrobacterium radiobacter) é um microorganismo Gram-negativo aeróbio do género Agrobacterium, grupo de bactérias fitopatogénicas presentes no solo, que tem sido implicado em infecções oportunistas nos humanos. Relata-se um caso clínico de peritonite bacteriana em criança de 5 anos com doença renal crônica em diálise peritoneal, que teve um factor epidemiológico de contato direto com o solo identificado. A infecção foi tratada com ceftazidima e piperacilina+tazobactam, sem reinfecções ou necessidade de remoção do cateter de diálise peritoneal.

Descritores: Rhizobium radiobacter; Peritonite; Diálise peritoneal; Criança; Relatos de casos

\section{INTRODUCTION}

Rhizobium radiobacter (Agrobacterium radiobacter) is an aerobic Gram-negative microorganism, of a group of phytopathogenic bacteria associated to opportunistic infections ${ }^{(1)}$. The first case of isolation described in humans was published in $1967^{(2)}$ and the first case of disease (endocarditis in a patient with prothetic valve), in $1980^{(3)}$. Bacteremia, urinary infection, endophthalmitis, pneumonia and peritonitis have been associated to this agent ${ }^{(1)}$.

\section{CLINICAL CASE}

A five-year-old girl with end-stage renal disease, secondary to congenital nephrotic syndrome diagnosed at 2 months of age, in nocturnal automated intermittent peritoneal dialysis since she was four-year-old, with no previous associated infectious events. A few hours before admission to hospital, the drained dialysis fluid was cloudy; she presented no fever or abdominal pain. There were no inflammatory signs in the peritoneal dialysis catheter inflow entry. Direct contact with soil in the week before onset of symptoms, when playing in the garden, was reported. In laboratory evaluation, cytological examination of dialysis fluid stood out with 1520 cells/mL, $90 \%$ of neutrophils, with no laboratory parameters of systemic bacterial infection; negative blood culture. She was initiated on antibiotic therapy with intraperitoneal cefazolin and ceftazidime. She presented progressive clinical improvement and the intraperitoneal fluid was clear on the fourth day of treatment. $R$. radiobacter was isolated in the dialysis fluid and was sensitive to ceftazidime, piperacillin + tazobactam, gentamicin and ciprofloxacin, and it was resistant to cotrimoxazole and tobramycin. Cefazolin was discontinued, and ceftazidime was maintained and associated to intraperitoneal piperacillin + tazobactam. She completed 21 days of double antibiotic therapy and the control bacteriological examination of the peritoneal dialysis liquid was negative after treatment. There was no need to replace the peritoneal dialysis catheter. After treatment, the child was clinically well, and was

\footnotetext{
' Centro Hospitalar Barreiro-Montijo, Hospital Nossa Senhora do Rosário - Lisboa (LI), Portugal.

${ }^{2}$ Hospital Reynaldo dos Santos - Vila Franca de Xira (VF), Portugal.

${ }^{3}$ Pediatric Nephrology Unit, Hospital de Santa Maria, Centro Hospitalar Lisboa Norte - Lisboa (LI), Portugal.

Corresponding author: Raquel Marta - Avenida Estados Unidos da América, 108, 2 Esquerdo - Campo Grande - CEP 1700-179 - Lisboa (LI), Portugal - Tel.: 00351964210838 - e-mail: rnunesmarta@gmail.com

Received: Mar 25, 2011 - Accepted: Jun 29, 2011

Conflict of interest: none
} 
submitted to renal transplant approximately two years after the described event.

\section{DISCUSSION}

Currently $R$. radiobacter is considered an opportunistic agent that affects mostly patients with chronic disease or immunosuppression ${ }^{(4)}$. In most cases the infection has been associated to presence of external plastic material, that is, central venous catheter, nephrostomy tube, peritoneal dialysis catheter or prosthetic valve. The frequency of this association could be related to the capacity of this microorganism to adhere to silicon tubes, like other agents, such as Staphylococcus aureus and Staphylococcus epidermidis ${ }^{(5)}$.

$R$. radiobacter bacteremia associated to central venous catheter is the most common presentation ${ }^{(6)}$. The mechanism of infection has not been well established yet, but the microorganism is found in the soil; in the literature, there is only one case reported as having direct contact with soil before onset of symptoms ${ }^{(1)}$, as in the present case. In 1997, the first case of peritonitis was described in an 11-year-old child with Down syndrome, chronic renal disease secondary to reflux nephropathy, and on peritoneal dialysis ${ }^{(7)}$. In this patient and in others described later ${ }^{(8-10)}$, it was necessary to remove the peritoneal dialysis catheter to control the infection. In the present case, the progression was favorable with no need to remove the catheter. Although there is no consensus as to requirement of catheter removal, it is recommended when there is clinical deterioration or the cultures remain positive 48 hours after initiating treatment ${ }^{(5)}$. The antibiotics prescribed for $R$. radiobacter infection are third-generation cephalosporins (most frequently), fluoroquinolones, broad-spectrum beta-lactam and the carbapenems. In clinical isolation of $R$. radiobacter, some strains produced enzymes that inactivate antibiotics, such as cephalosporinase, aminoglycoside-acetyltransferase and chloramphenicol-acetyltransferase ${ }^{(6)}$. In this case the isolated strain was sensitive to ceftazidime, piperacillin + tazobactam, gentamicin and ciprofloxacin, and resistant to cotrimoxazole and tobramycin. Double antibiotic therapy was chosen since the agent could develop resistance.

Preventive measures for infection in peritoneal dialysis patients are crucial to preserve the peritoneum. A case of peritonitis due to $R$. radiobacter in a child on peritoneal dialysis was successfully treated with no need to remove the catheter, highlighting the role of the opportunistic agents integrated to epidemiological environment.

\section{REFERENCES}

1. Chen CY, Hansen KS, Hansen LK. Rhizobium radiobacter as an opportunistic pathogen in central venous catheter-associated bloodstream infection: case report and review. J Hosp Infect. 2008;68(3):203-7.

2. Lautrop H. Agrobacterium spp isolated from clinical specimens. Acta Pathol Microbiol Scand Suppl. 1967;187:63-4.

3. Plotkin GR. Agrobacterium radiobacter prosthetic valve endocarditis. Ann Intern Med. 1980;93(6):839-40.

4. Edmond MB, Riddler SA, Baxter CM, Wicklund BM, Pasculle AW. Agrobacterum radiobacter: A recently recognized opportunistic pathogen. Clin Infect Dis. 1993;16(3):388-91.

5. Sood S, Nerurkar V, Malvankar S. Catheter associated bloodstream infection caused by R. radiobacter. Ind J Med Microbiol. 2010;28(1):62-4.

6. Amaya RA, Edwards MS. Agrobacterium radiobacter bacteriemia in pediatric patients: a case report and review. Pediatr Infec Dis. 2003;22(2):183-6.

7. Melgosa Hijosa M, Ramos Lopez MC, Ruiz Almagro P, Fernandez Escribano A, Luque de Pablos A. Agrobacterium radiobacter peritonitis in a Down's syndrome child maintained on peritoneal dialysis. Perit Dial Int. 1997;17(5):515.

8. Jankauskiené A, Baciulis V, Baliukynaité V, Kaltenis P. Peritonitis caused by Agrobacterium tumefaciens in a child on peritoneal dialysis. Nephrol Dial Transplant. 2003;18(11):2456-7.

9. Rothe H, Rothenpieler U. Peritonitis due to multiresistant Rhizobium radiobacter. Perit Dial Int. 2007;27(2):214-5.

10. Minguela Jl, de-Pablos M, Castellanos T, Ruiz-de-Gauna R.. Peritonitis by Rhizobium radiobacter. Perit Dial Int. 2006;26(1)112. 